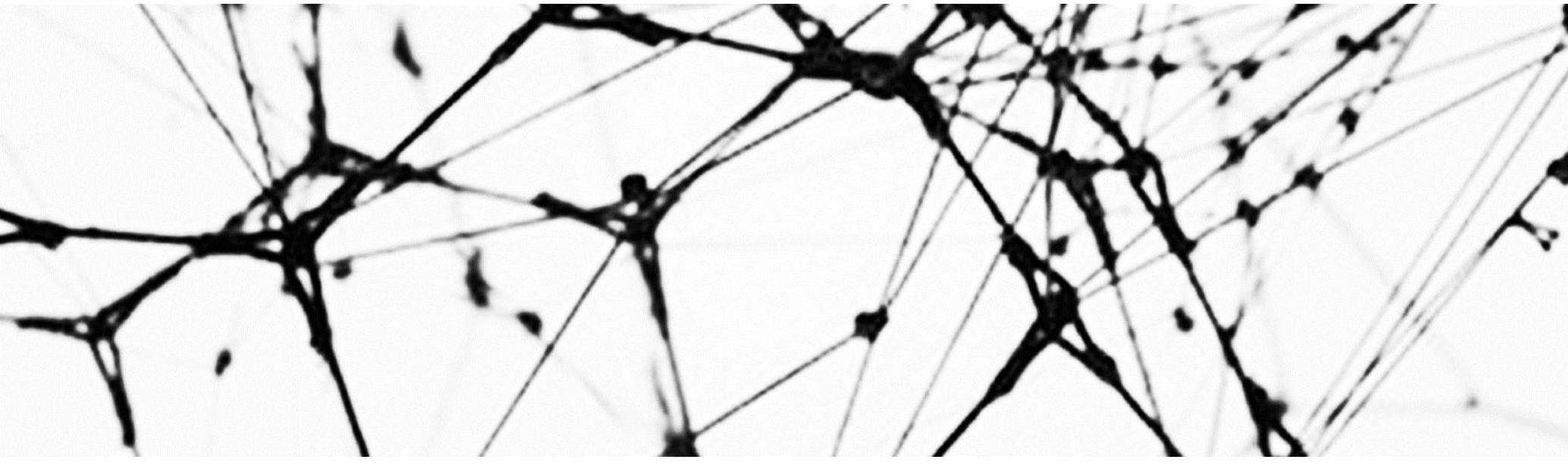

\title{
RELATO DE EXPERIÊNCIA: O TEMA DA CIDADANIA EM QUESTÃO. ELABORAÇÃO DE UMA SEQUÊNCIA DIDÁTICA POR ETAPAS SOBRE FILOSOFIA POLÍTICA
}

\author{
EXPERIENCE REPORT: THE SUBJECT OF CITIZIENSHIP IN QUESTION. \\ ELABORATION OF A DIDACTIC SEQUENCE BY STAGES ON \\ POLITICAL PHILOSOPY
}

Quézia Siqueira Pereira'
Angela Zamora Cilento $^{2}$

"Uma aula é uma espécie de matéria em movimento" Gilles Deleuze

Resumo: Este relato de experiência é resultado da participação de uma licencianda do curso de psicologia no PIBID de Filosofia na Universidade P. Mackenzie em São Paulo, cujo objetivo é de promover o ensino de filosofia por meio da sensibilização estética. Na escola parceira Major Arcy, escola pública da cidade de São Paulo, foi desenvolvido um projeto sobre cidadania que deu origem a uma sequência didática por etapas. A primeira consiste na implementação (planejamento, apresentação da proposta à equipe gestora e alunos), a segunda, na realização de várias dinâmicas de grupo, a próxima configurou-se pelo aprofundamento do referencial teórico, a quarta dedicou-se à produção estética pelos alunos. Houve um momento cultural que perfez a quinta etapa e por fim, a vivência do sociodrama fechou a sequência didática. Destarte, os alunos envolvidos passaram a valorizar o estudo de filosofia e se conscientizaram quanto à necessidade de sua participação na construção da sociedade civil. Além disso, puderam expressar-se por meio de manifestações artísticas. Este projeto permitiu revelar que a interconexão entre Filosofia e Psicologia pode promover resultados. O planejamento cuidadoso de cada etapa impactou

\footnotetext{
1 Graduada em Bacharel em Psicologia pela Universidade Presbiteriana Mackenzie e finalizando a Licenciatura em Psicologia pela Universidade Presbiteriana Mackenzie. E-mail: siqueiraquezia@gmail.com

2 Licenciada e Bacharel em Filosofia pela Pontifícia Universidade Católica de São Paulo e mestrado em Filosofia pela Pontifícia Universidade Católica de São Paulo. E-mail: angela.rezende@mackenzie.br

Revista Digital de Ensino de Filosofia - Santa Maria - vol.3. n.1 - jan. jun. 2017.
} 


\section{Introdução}

Desde 2013, os cursos de licenciatura da Universidade Presbiteriana Mackenzie foram agraciados com o Programa de Iniciação à Docência, fomentado pela Capes que "é uma iniciativa para o aperfeiçoamento e a valorização da formação de professores para a educação básica." (CAPES, 2016). Em outros termos, o PIBID tem como objetivo promover projetos de intervenção nas escolas da rede pública pelos licenciandos, sob a orientação dos professores coordenadores de área. Estes, por seu turno, são docentes da Universidade. Para cada projeto são desenvolvidos atividades de caráter didático-pedagógicas de modo a promoverem novas práticas de ensino que instiguem o saber e a prática da cidadania.

O trabalho tem por base o edital o Edital PIBID n¹ 1/2012 CAPES que, na subárea Filosofia:

Consiste no desenvolvimento de atividades que estimulem o estudo e instiguem à reflexão filosófica sobre o mundo em que vivemos, contemplando as relações entre as dimensões do humano e as diversas áreas da filosofia que se dedicam a fundamentar o pensamento sobre elas. Nesse sentido, pretende-se sensibilizar o aluno tanto para a relevância do estudo de filosofia quanto para a necessidade de uma sistematicidade na análise e na construção de um arcabouço conceitual específico da área, considerando o contexto social e cultural no qual os futuros profissionais atuarão, reconhecendo as dificuldades e desafios da prática pedagógica no ensino de Filosofia. No intuito de instrumentalizar a discussão e aprofundar as questões levantadas na sensibilização, serão propostas atividades que planejem e desenvolvam as habilidades de argumentação e raciocínio, tais como debates, exercícios e trabalhos escritos, socializados e discutidos a partir da pertinência argumentativa na produção dos textos. Elaboração de textos finais de cunho acadêmico. Considerando os objetivos, as atividades propostas pretendem desenvolver, inicialmente, uma problematização a respeito das questões éticas no mundo contemporâneo por meio da sensibilização estética. Nesse sentido, serão organizadas jornadas de sensibilização através de manifestações artísticas, música, teatro, entre outros., apresentando e produzindo diversas obras concretas e propondo debates sobre o sentido filosófico, ético e estético, analisando seus possíveis significados como manifestações da cultura e visando a compreensão das questões humanas e suas implicações para a construção de valores (PIBID\FILOSOFIA \MACKENZIE). 
Algumas das ações previstas concernem ao contato com o cotidiano escolar por meio de observações e participação nas relações de interação entre professor, aluno e profissionais da educação; Discutir e detalhar, em conjunto com docentes da Educação Básica envolvidos no projeto, as atividades a serem desenvolvidas em relação à sensibilização estética e às obras selecionadas; Preparação de atividades envolvendo textos, exercícios e outras que evidenciem para os alunos a construção de sentidos pertinentes às temáticas levantadas (PIBID\FILOSOFIA \MACKENZIE).

\section{Breve contextualização social da escola (do Projeto Político Pedagógico)}

A Escola Estadual Major Arcy está localizada no distrito de Vila Mariana, próximo à estação de Metrô Ana Rosa, Avenida Paulista e a Rua Vergueiro. No ano de 2015 a escola passou a fazer parte do Programa Ensino Integral (PEI). Há muitas áreas de recreação e lazer adequadas para os jovens, como SESC, Centro Cultural São Paulo, Bibliotecas Públicas e outros. A população preponderante é pertencente à classe média e os alunos que frequentam o ensino médio são provenientes de vários bairros da capital.

A escola mantém bom relacionamento com a comunidade: há uma grande participação da mesma nas atividades promovidas regularmente. Em sua grande maioria, os pais participam da vida escolar dos filhos. Frequentam reuniões e eventos como festas e projetos abertos à comunidade. Quase todos vêm à escola quando são chamados em situações extraordinárias, e alguns costumam procurar a escola independente de terem sido convocados, para conversar com a Equipe Gestora, a fim de acompanhar o aprendizado de seus filhos no ambiente escolar. Demonstram certa reticência com relação à participação no Conselho de Escola e na Associação de Pais e Mestres, pois muitos trabalham e encontram dificuldade em participar das reuniões. Mesmo assim, todos os anos, alguns pais se voluntariam para participar desses colegiados.

O prédio é bem conservado e as salas de aula são de tamanho adequado. Duas das dez salas de aula existentes na escola foram adaptadas Revista Digital de Ensino de Filosofia - Santa Maria - vol.3. n.1 - jan./jun. 2017. 
para receber o Acessa Escola e uma sala Multiuso, nesta sala os professores contam com um aparelho de data show. A escola conta ainda com mais cinco projetores data show distribuídos pelas demais salas de aula. Quatro dessas salas apresentam, ainda, caixas de som e tela retrátil, para uma melhor utilização do recurso. Dois notebooks e um netbook para uso dos professores e uma câmera filmadora digital.

\section{Etapas e relatos dos encontros}

Primeiramente, faz-se necessário comentar suscintamente, as observações realizadas na escola e em sala de aula durante as aulas de Filosofia ministradas pelo professor concursado. Estabelecemos, inicialmente, contato com a direção e mais diretamente com o professor. Planejamos, de acordo com as orientações do Caderno do Estado de São Paulo, a seleção dos conteúdos: eixos teóricos e temas transversais ligados ao ensinoaprendizagem da disciplina que poderiam ser despertados e trabalhados durante o semestre com o primeiro ano do ensino médio.

Depois do planejamento, fizemos a proposta à diretoria da escola que nos deu sua anuência. Diante disso, nos propomos nesse artigo, expor as etapas de aplicação do Projeto de Iniciação à Docência.

A primeira etapa de implementação foi a de explicitar os objetivos do subprojeto em filosofia. Começamos com uma apresentação geral do programa, dos licenciandos que participam do projeto, seu tempo de duração. (ZABALA, 2003, p.163) escreve que "é preciso que explicitem suas intenções educativas e como elas se concretizam no trabalho de determinados conteúdos".

O tema escolhido pelos estudantes para ser desenvolvido é o de Cidadania. A partir desse momento, perguntamos aos estudantes o que gostariam de fazer, a fim de que o tema pudesse provocar comprometimento e engajamento. Foram sugeridos: teatro, debate, música e visita educativa ao museu da imigração. 


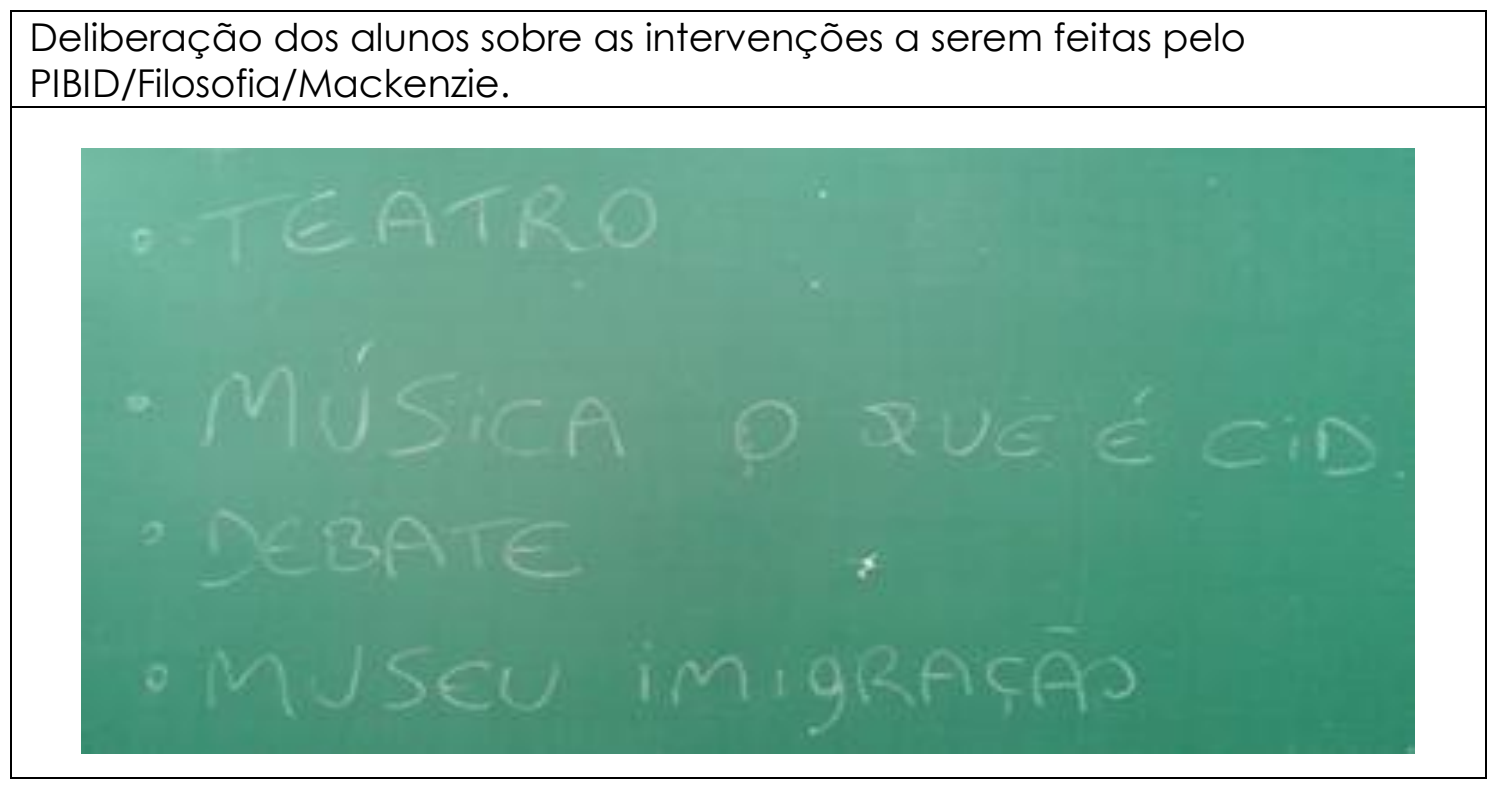

O ensino da filosofia por meio da sensibilização estética impacta os estudantes em seu sentido formativo: posto que se inscreve enquanto constituinte, no sentido iluminista do termo, do sujeito e do cidadão: a ampliação do universo cultural, entendido como um espaço de diversas leituras, entendimento e reflexão sobre o real que se concretizam nas e por meio das artes/manifestações artística, em primeiro lugar. É possível realizar interação de conteúdo já proposto pelo professor e utilizar a sensibilização estética como fator agregador para o processo de aprendizagem.

Entende-se que é de suma importância articular a sua formação escolar acadêmica com a realidade vivida, CREMA (1998), discorre que o estudante é como o fruto de uma rede de configurações vinculares, ele constrói uma imagem de si mesmo de acordo com: as diversas identificações e projeções; seus êxitos e fracassos nas diferentes áreas da vida real. Fazer a interlocução desses estágios da realidade com a escola é um desafio diário que a escola tem enfrentado.

Para a segunda etapa - depois de colocadas informações importante acerca do projeto de trabalho, realizado contato com a direção, professorsupervisor e estudantes - utilizaram dinâmicas de grupo, como forma de aquecimento para os debates que se realizaram posteriormente. Essa escolha 
de metodologia acontece para atrair a participação e envolvimento em relação ao processo de ensino-aprendizagem.

OUTEIRAL (1989) destaca sobre a importância do rapport para com o grupo, sendo que, as atitudes, posicionamento e a linguagem corporal do facilitador podem funcionar como concorrente para acentuar ou desfazer as primeiras impressões, tanto as positivas como as negativas referentes ao encontro entre facilitador e participantes.

O posicionamento do professor deve ocorrer de forma a favorecer interações tanto individuais como em vários outros níveis de interação, não somente em relação ao conteúdo, mas no relacionamento diário com seus colegas. (ZABALA, 2003, p. 182-183) afirma que cabe ao profissional desenvolver um repertório inicial de observação e sua prática deve ser constituída de "elasticidade". Procuramos despertar suas habilidades argumentativas e as de escuta, como forma de "levar sua experiência e os instrumentos que lhe permitam construir uma interpretação pessoal e subjetiva daquilo de que se trata".

Mais uma vez OUTEIRAL (1989) sinaliza que para cada papel desempenhado, o participante faz um depósito de sua opinião, e cada uma é carregada de impulsos, ansiedades, fantasias, emoções, paixões e pensamentos. Diante disto, ao facilitador confere o papel de âncora, de mediador dos acontecimentos grupais de forma a assegurar que o processo de ensino-aprendizado ocorra. Deve também catalisar e intermediar os debates entre os participantes com intuito de promover reflexões ligadas à atualidade e pensar acerca do seu papel na sociedade, como um cidadão consciente.

Sobre o significado da palavra facilitador lembra-nos o de facilitar a dor "que traz implícita a ideia de que os grupos já detêm em si tais capacidades ou características, que precisam apenas ser reveladas ou desveladas" (ANDALÓ, 2006, p.79). Para complementar tal concepção, Marilena CHAUí (1980) comenta que: 
Ao professor não cabe dizer 'faça como eu', mas 'faça comigo'. O professor de natação não pode ensinar o aluno a nadar na areia, fazendo-o imitar seus gestos, mas leva-lo a lançar-se n'água em sua companhia para que aprenda a nadar lutando contra as ondas, fazendo seu corpo coexistir com o corpo ondulante que o acolher e repele, revelando que o dialogo do aluno não se trava com seu professor de natação, mas com a água (p. 37).

Por mais que o desempenho deste papel ocorra, ao provocar o grupo, reações diversas e dificuldades se apresentaram. Uma delas concerne à própria condução dos debates. Todavia, é importante lembrar que todos os participantes desempenhem papéis importantes dentro do grupo: estes papéis não são fixos, mas são constituintes do processo grupal, e assim, podem ser observados os papéis: silencioso, o líder de mudança, o líder de resistência, o bode expiatório e o porta voz. Todos estes papéis se constituem e existem em cada grupo. DELEUZE (1989) ainda complementa citando que "há deslocamentos dos centros de interesses, isso forma uma espécie de tecido esplêndido, uma espécie de textura".

Paulo FREIRE (1987) nomeia esse jogo de ensino-aprendizado como problematização. Para que ocorra a problematização, sabe-se que é importante a comunicação por meio da linguagem. Para complementar essa ideia, VYGOSTKY (2001) afirma que a linguagem exerce um papel como objeto de mediação, e que todo o domínio do conhecimento humano, se dá e se deu durante todo o processo civilizatório. Já, na contemporaneidade, podemos afirmar que não há linguagem, mas linguagens e dentre elas, a linguagem artística se incorpora enquanto expressão privilegiada da subjetividade. A linguagem, nas palavras de (HEIDEGGER,1995, p.31), são como uma "expressão e comunicação dos movimentos da alma guiados pelos pensamentos; uma representação e uma apresentação do real e do irreal". A relevância da linguagem remonta à filosofia aristotélica que considera que

Assim, o homem é um animal cívico, mais social do que as abelhas e os outros animais que vivem juntos. A natureza, que nada faz em vão, concedeu apenas a ele o dom da palavra, que não devemos confundir com os sons da voz. Estes são apenas a expressão de sensações agradáveis ou desagradáveis, de que os outros animais são, como nós, 
capazes. A natureza deu-lhes um órgão limitado a este único efeito; nós, porém, temos a mais, senão o conhecimento desenvolvido, pelo menos o sentimento obscuro do bem e do mal, do útil e do nocivo, do justo e do injusto, objetos para a manifestação dos quais nos foi principalmente dado o órgão da fala. Este comércio da palavra é o laço de toda sociedade doméstica e civil. (ARISTÓTELES, 2016, p.11)

Para o pensador, os homens são seres sociáveis por natureza, assim como as abelhas e as formigas: sempre estiveram juntos, porém somente os homens possuem o dom da palavra que revela nosso conhecimento sobre as coisas e também nosso juízo. Enunciamos pela palavra o que achamos sobre uma coisa ou outra, se achamos certa ou errada, boa ou má, bonita ou feia. Os animais não fazem juízo de valor, e por isso também não julgam algo como justo ou injusto. Outra afirmação relevante nessa citação consiste na ideia de que a sociedade está calçada na fala dos homens que estabelecem por ela, suas relações.

A primeira dinâmica realizada teve como objetivo a promoção de maior interação entre os alunos: formamos um grande círculo no pátio da escola e cada participante se apresentou, comentou em qual cidade nasceu e sua idade. Depois dessa breve apresentação um dos participantes ficou no centro e disse uma característica (física, sentimental, etc...), por exemplo: pessoas que usam óculos. Feito isso, as pessoas que se identificam com esta característica saem de seus lugares no círculo e procuram outro lugar para se encaixar novamente. Porém, sempre uma pessoa (que sobra) fica no centro e a cada rodada uma nova pessoa fala mais uma característica.

Nessa dinâmica, ressaltamos algumas das características que foram usadas como pontos de identificação entre eles: menina, óculos, boné, alto, quem gosta de funk, quem é legal, quem gosta do livro de Percy Jackson, quem tem cabelos cumpridos, quem gosta de estudar, quem é baixo, ciumento, sensivel, quem gosta de futebol, quem tem 15 anos, quem tem mais de 15 anos, quem é dog "pega geral" (sic), quem gosta de hip hop, quem tem cabelo enrolado, quem está com casaco amarrado na cintura, quem gosta de Harry Potter, quem usa alargador na orelha, quem é egoísta, quem já foi em baile de favela, quem usa aparelho, quem está com algo da marca Adidas, quem está de shorts, quem tem bunda grande, quem está com calça Revista Digital de Ensino de Filosofia - Santa Maria - vol.3. n.1 - jan./jun. 2017. 
jeans, tênis preto, unha pintada, calça leg, quem usa piercing, quem é virgem, quem está com tênis colorido, quem gosta de rock, quem é corintiano, quem joga vôlei, quem é brasileiro, quem é inteligente, quem gosta de forró, por exemplo.

Logo que a dinâmica foi finalizada, perguntamos aos participantes se eles conseguiram identificar os motivos e justificativas do por que se realizou a dinâmica. Ficando claro que precisavam se conhecer melhor.

Assim como os autores BERGER E LUCKMANN (1993) definem, Madalena FREIRE (1992) também escreve que para que ocorra a socialização de uma pessoa, ocorrem dois processos, sendo eles: $O$ grupo primário é aquele que se constitui por vínculos afetivos. Ex: grupos de parentesco ou amizade. Já o grupo secundário é mediado por vínculos profissionais. Ex: grupos institucionais como, por exemplo, a escola. A pessoa inicialmente se identifica, se reconhece como parte constituinte do grupo familiar para depois, em outro momento, formar amizades, conhecer outras pessoas que não são do seu grupo de socialização primária.

Em outro encontro propusemos uma dinâmica no pátio da escola a fim de trabalhar a integração entre os estudantes. Cada um fala algo que gosta ou não gosta para o restante do grupo que está em círculo. Cada pessoa que se identifica com o que a pessoa falava, levanta uma de suas mãos. Sendo assim, a pessoa que fala escolhe uma dessas pessoas que levantou a mão e faz um risco no chão com um giz em direção à pessoa escolhida (de forma que ao final da dinâmica é perceptível a forma uma rede riscada no chão).

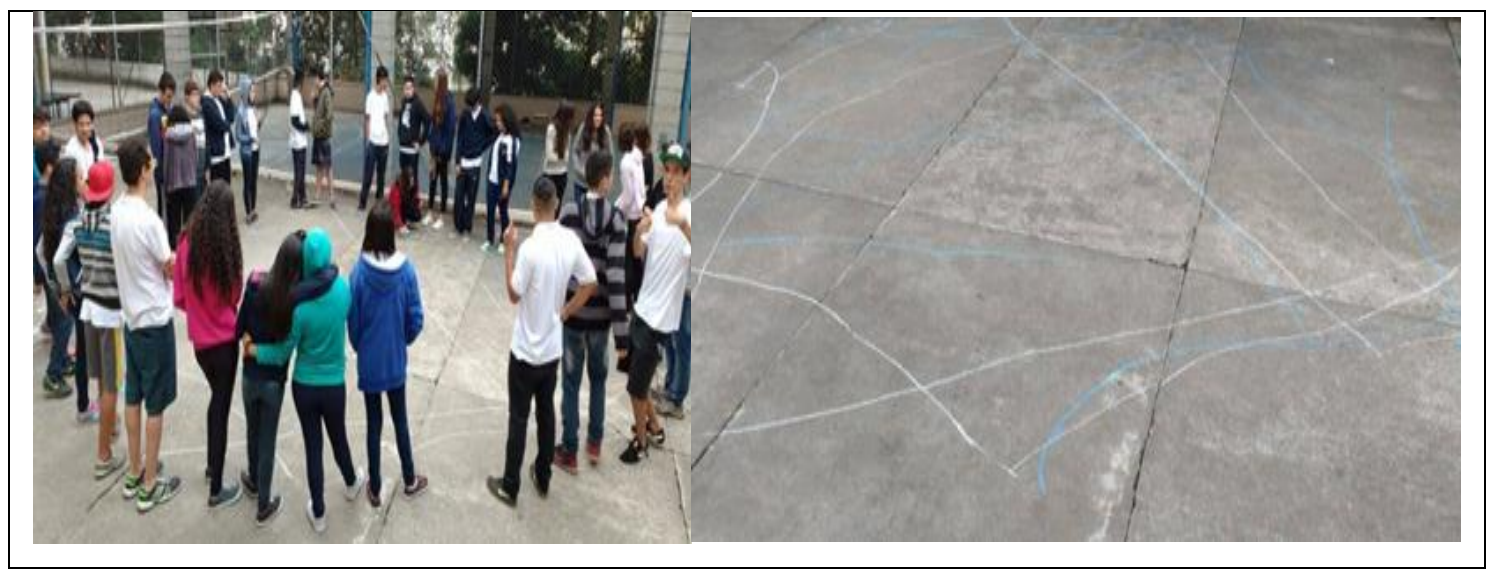

Revista Digital de Ensino de Filosofia - Santa Maria - vol.3. n.1 - jan./jun. 2017. 
O objetivo da dinâmica foi expresso para todos, objetivando frisar a ideia de que temos pontos em comum e que eles refletem tanto coisas que gostamos como as que não gostamos. Nessa dinâmica, foram citados: ler, tomar suco, skate, escutar música, fazer esportes, gostar do frio, assistir ou ler os filmes \ivros do Percy Jackson, mexer no celular, ouvir reggae, comer, comer fruta, assistir as branquelas, assistir séries, dormir, gostar de doces. Sobre o que não gostam: matemática, legumes, barulho e da colega de classe.

Mais a frente, como estratégia de trabalho, sugerimos mais uma dinâmica de grupo, agora com base na proposta de KORCZAK (2016) que, na qualidade de diretor de um orfanato instituiu um tribunal de arbitragem de crianças, no âmbito do qual as próprias crianças avaliavam as causas apresentadas por elas mesmas. Esta dinâmica configura-se com a apresentação um caso que precisa ser julgado e divide-se a sala em dois espaços: um lado julgará e elaborará argumentos possíveis para condenar e, - outro, levantará argumentos possíveis para absolvição. Escolhe-se uma pessoa para tirar fotos e outra para fazer um relato do que está acontecendo durante a dinâmica.

Na E.E. Major Arcy, foi proposto o seguinte caso: Um homem de 45 anos que nasceu em Luanda, negro, vendedor ambulante e imigrante ilegal, foi preso por vender fones de ouvido no centro de São Paulo.

Iniciamos o debate entre os grupos. O de defesa declara que a vítima veio para o Brasil na tentativa de uma melhoria de vida - para si e sua família. O preso buscava ter direito à moradia, além de melhores condições financeiras. Argumentaram também que este homem está ocupando o lugar de um assassino que devia estar na cadeia, já que ele estava trabalhando ainda que informalmente. $\bigcirc$ outro apresenta as seguintes justificativas: este o homem está errado, pois entrou de uma forma ilegal no país, e vende produtos que não tem garantia e nem qualidade. Ainda colocam que o réu deveria ter procurado um emprego primeiro antes de ser vendedor ambulante.

Diante dessa situação, pede-se que os grupos invertam os papéis para pensar na outra condição da qual estavam defendendo. Porém, neste Revista Digital de Ensino de Filosofia - Santa Maria - vol.3. n.1 - jan./jun. 2017. 
momento houve resistência dos grupos: afirmaram que, se fossem pensar na outra posição, encontrariam os mesmos argumentos já apresentados pelo grupo anterior. Por esse motivo se negaram a continuar a dinâmica.

Nesse momento, o professor de Filosofia trouxe sua contribuição - ele assinalou e ponderou que, é preciso primeiro para prender alguém é necessário ter um fato e uma motivação (por que prender, qual a posição, a condição por ser negro, etc). O grupo que pertencia à defesa procurou demostrar os motivos pelos quais ele não deveria ser preso, enquanto o de acusação usou o argumento de que ele está praticando uma atividade ilegal, além de estar ilegalmente no país. "Talvez por isso o debate não tenha sido polêmico, pois pegaram viés diferente para argumentar aqui. Não tem como decidir, pois estão sendo usados pesos diferentes para julgar" (sic).

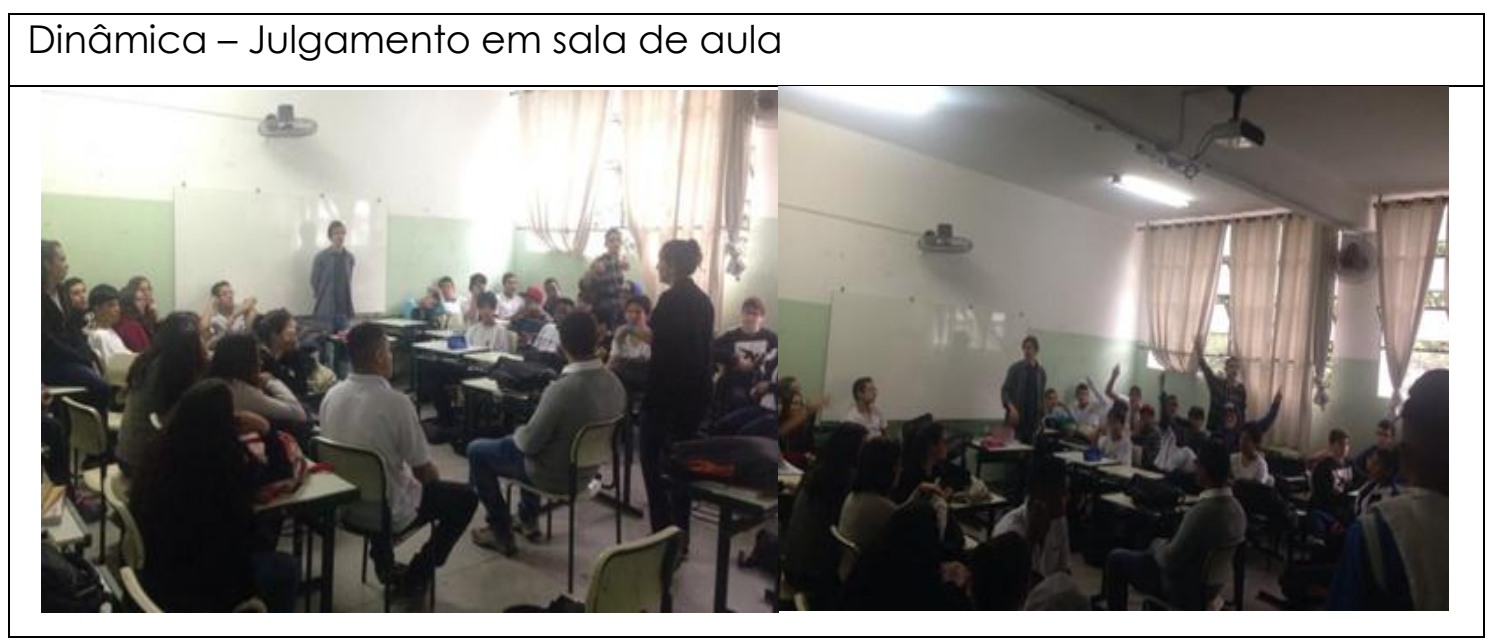

É importante pensar acerca da organização social da classe ou formas de agrupamento para uma melhor compreensão do significado do aprendizado e mobilização de conhecimento. Deve-se levar em consideração estilos e ritmos que abarcam o ensino-aprendizagem. Sendo assim, "para poder atender à diversidade dos alunos e a aprendizagem de conteúdos de diferentes naturezas, é preciso haver estruturas organizativas complexas que contemplem as potencialidades das distintas formas de agrupamento" (ZABALA, p. 187, 188).

A terceira etapa configurou-se com o desenvolvimento do referencial teórico. A autora escolhida para estudar acerca do tema cidadania durante 
o semestre foi Agnes HELLER (1972), filósofa húngara. O texto utilizado foi: O quotidiano e a história. Foram selecionados alguns fragmentos e palavraschave, tais como: fenômeno social, direito à vida, exercício de direitos, deliberação de questões, liberdade, dignidade e participação.

A quarta etapa relaciona-se diretamente com o PIBID. Pedimos aos estudantes que se utilizem de diversos tipos de materiais, tais como: tintas, massinha, cola, tesoura, recortes, lápis de cor e giz de cera para demostrarem uma situação que envolvesse a cidadania. Eles poderiam utilizar a cartolina da forma em que quisessem. Poderiam fazer esculturas, acrósticos, pinturas, desenhos, quadrinhos, poemas, letras de músicas, enfim, o que achassem que pudesse de alguma forma sinalizar o que estavam pensando a respeito do tema.

Resumidamente apresentamos as produções realizadas: um dos grupos se propôs em demostrar a cidadania fazendo desenhos ligados à bandeira LGBT. Quando apresentaram falaram sobre homofobia, feminismo, preconceito, exclusão, luta por direitos iguais e questionaram o "porque as pessoas não podem ser do jeito que são" (sic). 
Produções sobre cidadania - cidadania fazendo desenhos ligados à bandeira LGBT. Quando apresentaram falaram sobre homofobia, feminismo, preconceito, exclusão, luta por direitos iguais.

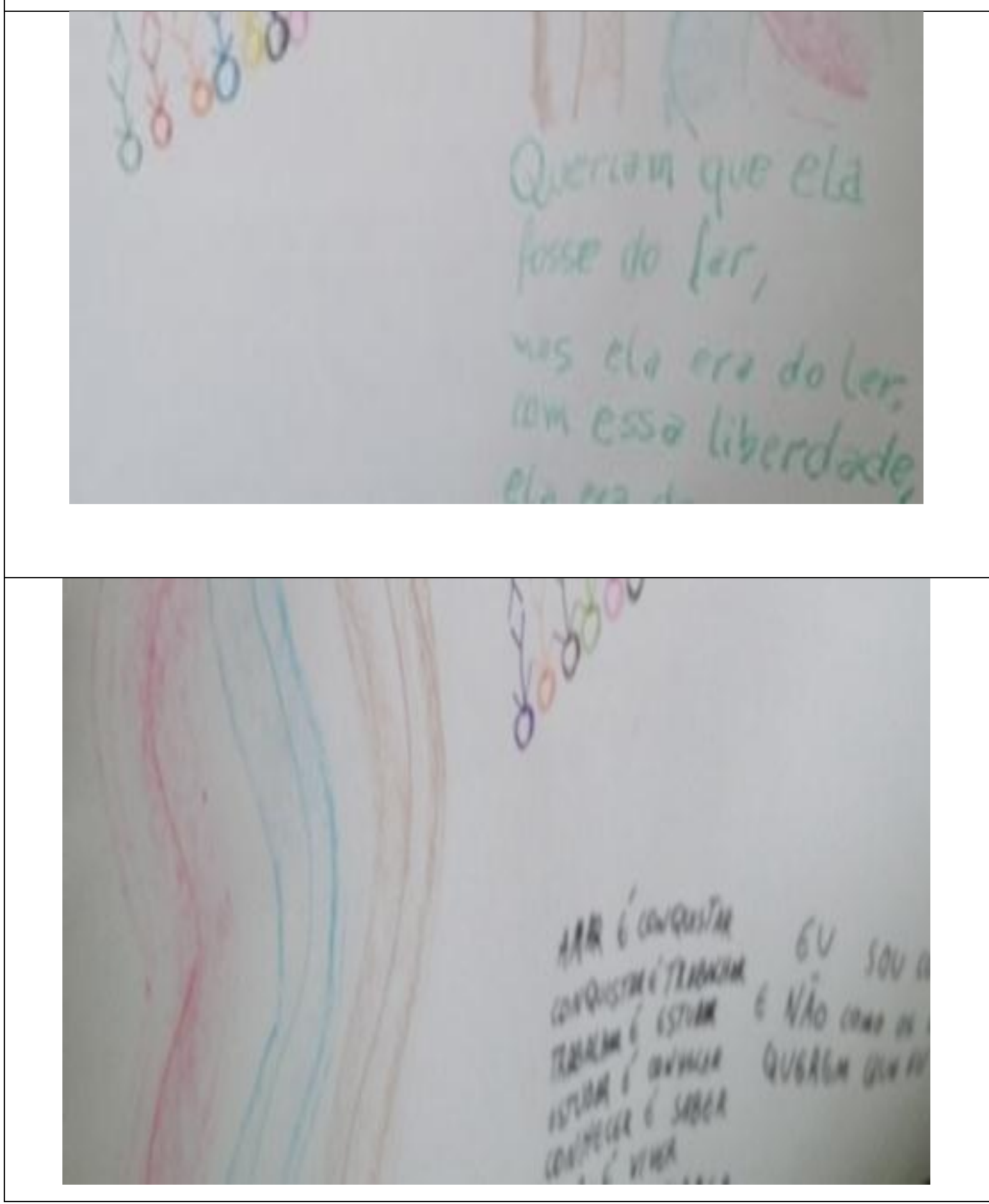

Outro grupo expressou com cartazes ilustrados. Questionaram sobre os princípios de igualdade, respeito e diversidade cultural.

Revista Digital de Ensino de Filosofia - Santa Maria - vol.3. n. 1 - jan./jun. 2017. 


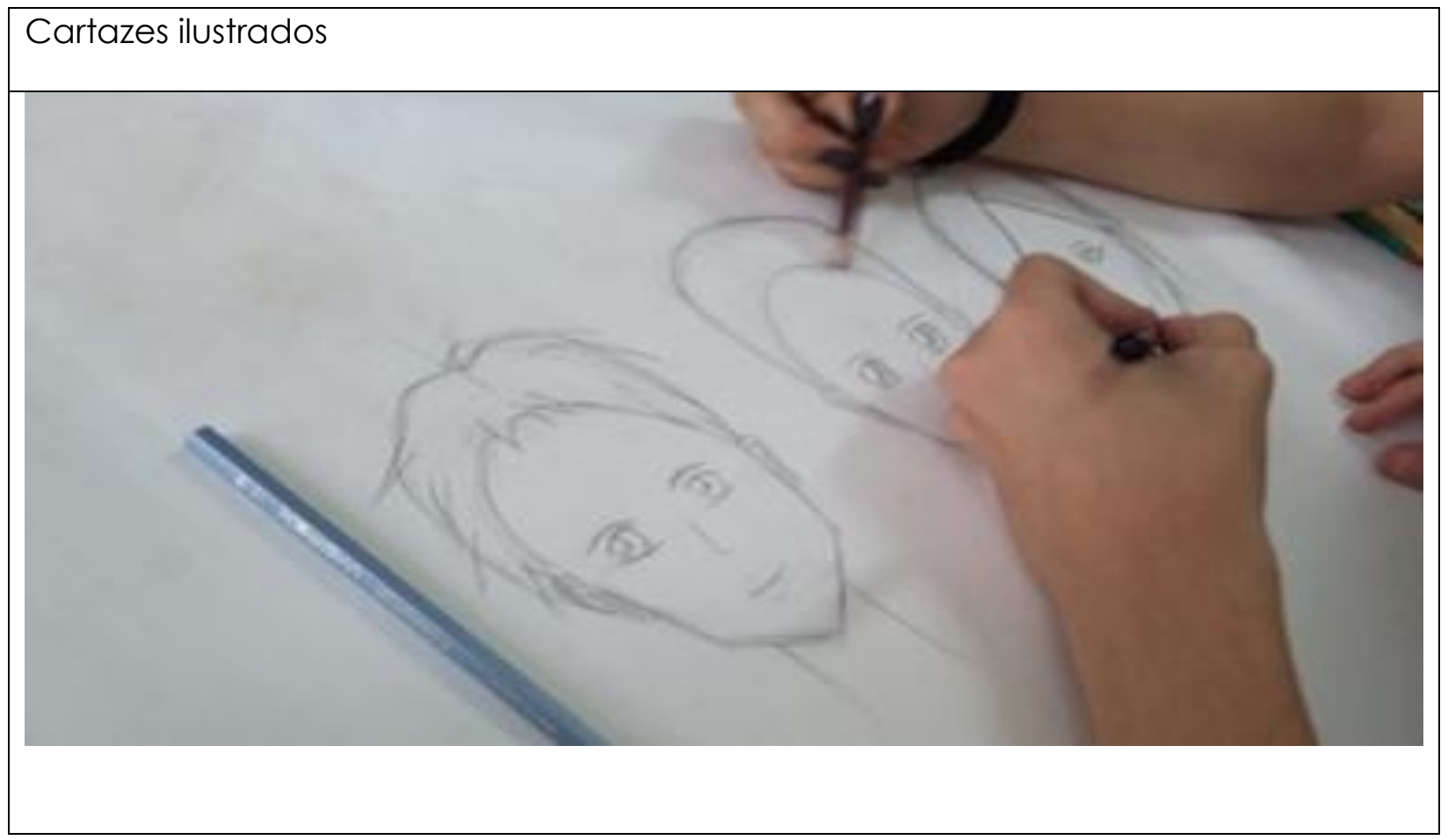

O próximo grupo expressou-se por meio de tintas nas mãos pintadas no cartaz. Falaram sobre as diferentes raças, direitos iguais e preconceito.

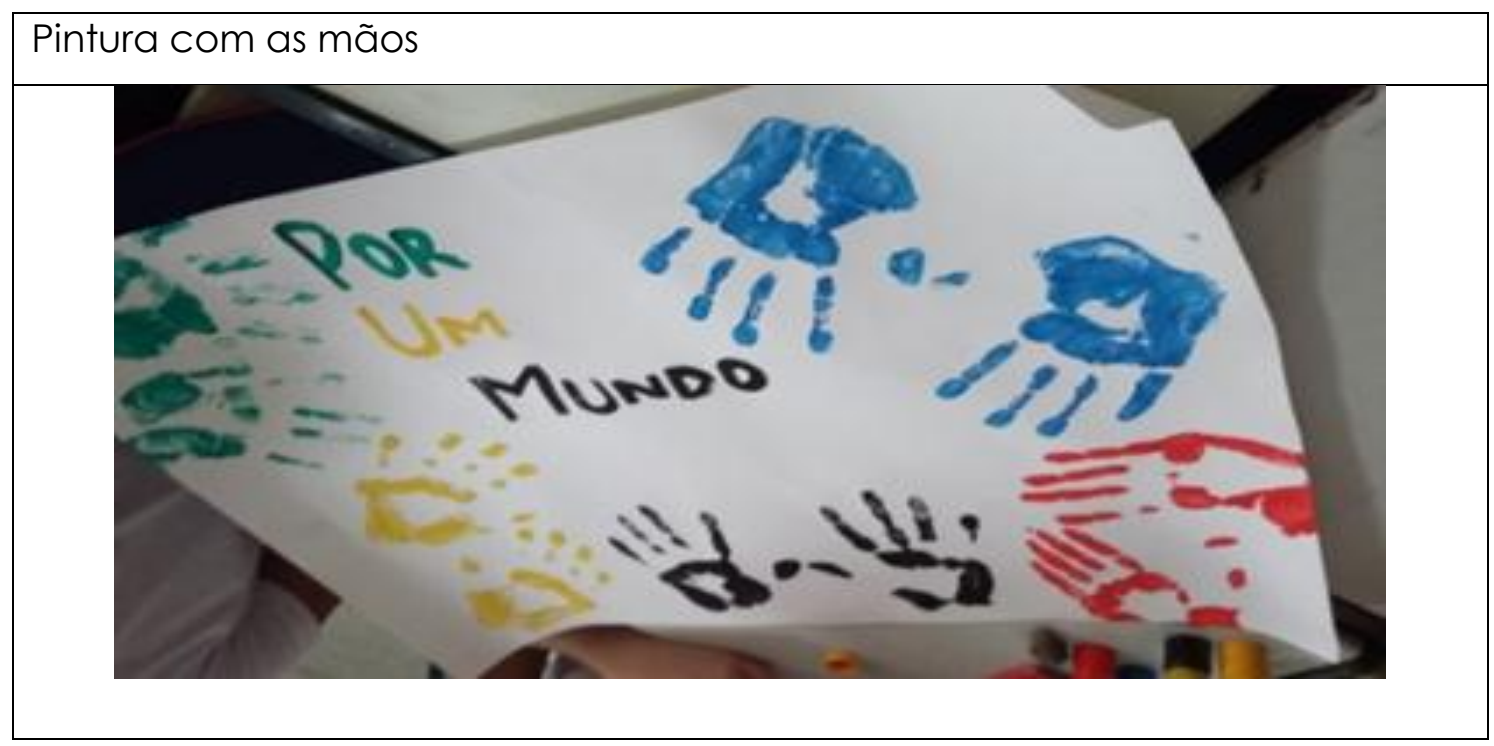

Outro fez desenhos representando que "um precisa do outro" (sic), diferentes culturas e que "nem todos reconhecem seus direitos" (sic). O último grupo também fez um desenho, sobre uma manifestação. Falaram sobre protesto, voto, exclusão, poder e política. 


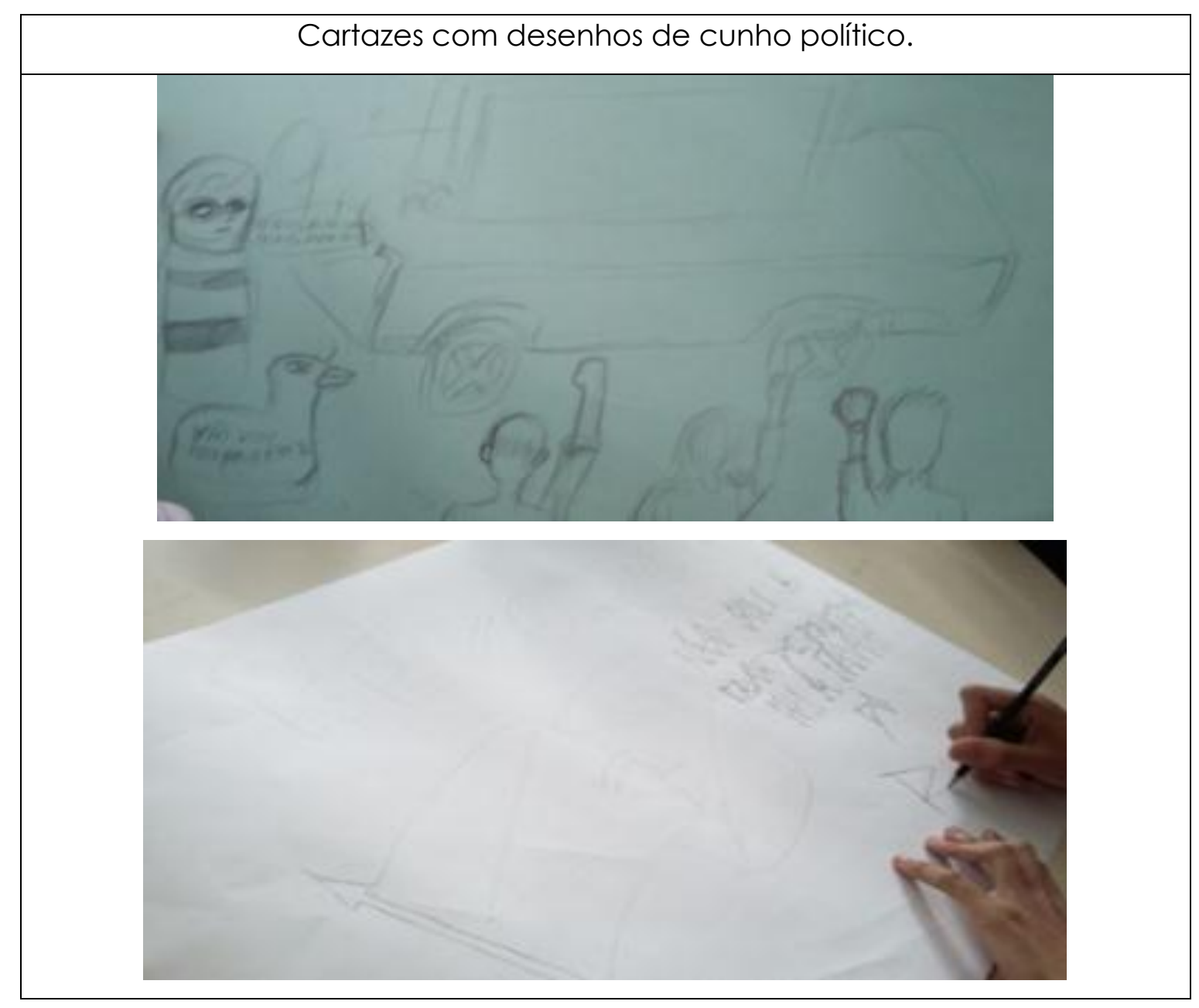

Depois, os próprios estudantes pensaram em um critério para escolher um dos cartazes para aprofundamento e articulação com o referencial teórico sobre cidadania. "Numa aula, cada grupo ou estudante pega o que Ihe convém" DELEUZE (1989). Não podemos dizer que uma aula convém a todos que participam. Cada um tem um tempo para entender e digerir sobre tudo o que foi conversado. O filósofo comenta que há um acordar misterioso que envolve esse processo, acordar em tempo de captar o que lhe convém pessoalmente. É por isso que o público variado é muito importante. Mesmo que sejam de cidades diferentes, etnias, idades, entre outros.

O fechamento desta etapa, a penúltima, seria a de visitarmos o Museu da Imigração, e por questões relacionadas ao transporte não foi possível concretizá-la. Porém, conseguimos uma parceria com o Sesc Vila Mariana que na época estava com a exposição: Provocar Urbanos. 


\begin{abstract}
A exposição Provocar Urbanos: Inquietações Sobre a Cidade que propõe reflexões e ações sobre o direito pleno à cidade, considerando as dimensões individuais, sociais e políticas ao problematizar as potencialidades e desafios do espaço urbano. Composta por nove instalações criadas por artistas e coletivos contemporâneos, a exposição propõe dialogar com o público sobre as complexas configurações da vida na metrópole, expressando de forma crítica e poética elementos naturais e sociais que estão dialeticamente envolvidos nessa equação. Dividida em eixos, as discussões levantadas pelo conjunto de obras tangenciam temáticas como a mobilidade, a sustentabilidade, a questão hídrica e a ocupação de espaços públicos e privados (ADINOLFI, 2016).
\end{abstract}

Nesse dia de visita ao Sesc foi possível refletir acerca da cidade: como vivem as pessoas na cidade? Como exercer sua cidadania? Há outras formas de se viver na cidade? Como? Há pessoas excluídas? De que forma? Por qual razão? É justo? Se sim, por que, se não por quê? É possível viver em conjunto?

E por fim, a sexta etapa empreende o fechamento das atividades do primeiro semestre de 2016. Foi proposto um breve sociodrama de cunho educativo. O objetivo da atividade de promover mais uma vez espaço de reflexão, fixação e aprofundamento acerca do que pôde ser apreendido durante todo o semestre. Este momento foi vivenciado de uma forma mais lúdica, descontraída, com utilização não somente da voz, ou papel, mas também do corpo.

Ressaltamos que a importância desse momento, não está em submeter as apresentações a um critério de avaliação, mas antes recuperar a incorporação do referencial teórico pelos alunos, bem como a preocupação de promover um feedback relacionado ao aprendizado e em relação em como foi fazer aquela atividade: se foi difícil e por quê, se foi legal e por quê, como foi fazer em grupo, e que nota se dariam - enquanto processo autoavaliativo (0-10).

\title{
4. Algumas considerações
}

Nessa proposta de trabalho, buscamos seguir uma linha de desenvolvimento de atividades que estimularam o estudo e instigaram e estimularam a reflexão filosófica sobre $\circ$ mundo em que vivemos, 
contemplando as relações entre as dimensões do humano e as diversas áreas do conhecimento e que se dedicam a fundamentar o pensamento sobre elas.

Nesse sentido, a sensibilização estética serviu como ferramenta de intervenção e reflexão para o ensino de filosofia com o tema da cidadania para a primeira série do ensino médio na E.E Major Arcy - escola pública da cidade de São Paulo. Para a execução desse projeto, planejamos uma sequência didática constituída por seis etapas. A primeira referiu-se à de sua implementação. Foram realizadas reuniões de planejamento, de seleção de conteúdos a serem ministrados e sua apresentação à equipe gestora e aos estudantes. Podemos reiterar o professor-supervisor como co-formador dos licenciandos para sua atuação profissional enquanto futuros docentes, compactuando com os objetivos propostos do PIBID. A segunda etapa permitiu, por meio das dinâmicas executadas, o aprimoramento da interação entre os discentes, e da capacidade argumentativa, colaborando para seu processo de formação. A terceira fez com que licenciandos e discentes se debruçassem sobre o referencial teórico dos autores selecionados, proporcionando a apropriação desse conteúdo. A quarta revelou por meio da linguagem artística, a expressão da subjetividade dos alunos e dos pontos de vista adotados por eles. A quinta permitiu a vivência de um espaço para além da sala de aula, proporcionando questionamentos sobre o papel do cidadão na construção de uma sociedade mais justa e igualitária. Por fim, com a contribuição mais ativa da Psicologia, o ensino de Filosofia política tornou-se significativo por meio do psicodrama, além das técnicas de condução de grupos e problematizações durante todo o semestre.

O uso dos textos de autores tanto de Filosofia como os de Psicologia, acrescentaram qualidade à formação dos licenciandos, pois esta contribuiu com as concepções de 'homem' derivadas da investigação teórica, bem como com técnicas empregadas para essa sequência didática. Promovemos assim um encontro profícuo desta interface - Filosofia e Psicologia. Propiciamos um ensino significativo para os estudantes e abrimos horizontes para se criarem outros projetos de intervenção que estejam focados na renovação dos instrumentos do saber e das suas estratégias, pois sabemos da complexidade 
que envolve o cotidiano escolar e das questões desafiadoras no que tange à educação.

\section{Referências}

ADINOLFI, M. Exposição Provocar Urbanos: Inquietações sobre a Cidade. Sesc Buntantã. São Paulo. 2016. Disponível em: < http://www.mauricioadinolfi.com/> Acesso em 30 jun 2016.

ANDALÓ, C. "O papel do coordenador de grupos". In: Mediação grupal: uma leitura histórico-cultural. São Paulo: Ágora, 2006.

ARISTÓTELES. A Política. Disponível em: <https://docviewer.yandex.com/?url=yadiskpublic\%3A\%2F\%2FoFdqAy\%2BFxv5u W5IP6Gk8qnAGVWXZ88kRXv2ZI2q6Y8M\%3D\&name=Arisł\%C3\%B3teles\%20\%20A \%20Pol\%C3\%ADtica.pdf\&c=56ccfdabf3bl>. Acesso em 10 jun 2016.

BERGER, P. L; LUCKMANN, T. A Sociedade Como Realidade In: A Construção Social Da Realidade. Petrópolis, Vozes, 1973.

CHAUÍ, M DE S. Ideologia e Educação. Educação \& Sociedade. n5, pp. 24-40. 1980.

CREMA, M. A Psicopedagogia Institucional na escola: algumas considerações teóricas e práticas. In: BUTELMAN, Ida (org.). Pensando as Instituições - teorias e práticas em educação. Porto Alegre: Artmed, 1998.

DELEUZE, G. Abecedário P. de Professor - Entrevista com Deleuze. Ed Montparnasse, $\quad$ Paris. $1989 . \quad$ Disponível em: <https://www.youtube.com/watch?v=JagcUtuyd4o>. Acesso em 28 mar 2016.

FREIRE, M. Escola, Grupo e Democracia. Síntese do texto de Elaine Tavares, a partir da palestra de Madalena Freire no painel Escola, Grupo e Democracia. Transcrição: Marilene Pereira e Maria Inês Petry. Porto Alegre. 1992.

FREIRE, P. Pedagogia do oprimido. 17. ed. Rio de Janeiro: Paz e Terra, 1987.

HEIDEGGER, M. Língua de tradição e língua técnica. Lisboa: Vega Passagens, 1995.

HELLER, A. O quotidiano e a história. Rio de Janeiro: Paz e Terra. 1972.

KORCZAK, J. Janusz Korczak. Disponível em: <https:// http://pt.wikipedia.org/wiki/Janusz_Korczak>. Acesso em 03 Mar 2016.

OUTEIRAL, J. O Trabalho Com Grupos Na Escola. São Paulo: Scipione. 1989. 
PIBID $\backslash F I L O S O F I A \backslash M A C K E N Z I E$.

Disponível

em:

<https://www.facebook.com/pibidfilosofiamackenzie/>. Acesso em 01 Jan 2016.

VYGOTSKY, L. S. Pensamento e linguagem. Trad. Ridendo Castigat Mores 1. ed. E-Book: Fonte digital, 2001. Disponível em: <https:// http://www.jahr.org>. Acesso em 06 Mar 2016. 